\title{
The use of fibrin sealant as a glue for septoplasty and conchotomy*
}

\author{
Michael Vaiman, Shlomo Sarfaty, Ephraim Eviatar \\ Department of Otolaryngology - Head and Neck Surgery, Assaf Harofeh Medical Center, Affiliated to Sackler \\ Faculty of Medicine, Tel Aviv University, Israel
}

\begin{abstract}
SUMMARY
Objective: The aim of our study was to investigate glue properties of a fibrin sealant in cases of septoplasty and conchotomy.

Design: Double-blind prospective randomized study.

Materials and Methods: A study of 146 patients (80 M, 66 F) who underwent septoplasty and conchotomy was performed in Assaf Harofeh Medical Center Tzrifin, Israel. The patients were divided randomly into two groups: Group I $(n=74)$ underwent septoplasty with transseptal suturing, and conchotomy with glue as a haemostatic. Group II (n=72) underwent septoplasty and conchotomy with glue as a haemostatic as well as septal cartilage and mucoperichodrial flaps sealant (no transseptal suturing). The glue was based on a concentrate of human clottable proteins and purified native human thrombin.

Results: Our results showed complete healing in both groups without significant differences. One late postoperative nasal bleeding occurred in group I, and none in group II.

Conclusion: We conclude that the use of second-generation glue in endonasal surgery is well suited to stop nasal bleeding and seal intranasal flaps. Moreover, it might help to avoid transseptal suturing.
\end{abstract}

Key words: septoplasty, fibrin sealant, endonasal surgery

\section{INTRODUCTION}

During five years since our publications on the use of fibrin sealant as hemostatic in endonasal operations ${ }^{(1,2)}$ and endoscopic sinus surgery ${ }^{(3)}$ the usefulness of this hemostatic technique was well established ${ }^{(4-6)}$. While the hemostatic properties of the fibrin sealant are well established, the question remains over its fixing properties.

Deviated nasal septum and hypertrophy of inferior conchae are treated surgically using submucosal resection of nasal septum (septoplasty, nasal septal reconstruction), and reduction of the nasal conchae (conchotomy) ${ }^{(7)}$. All these surgical operations may produce bleeding, swelling and a postoperative intraseptal hematoma. Therefore, all these operations, if not performed by laser, may result to the use of various types of nasal packing or application of fibrin sealant.

There were several reports on the use of fibrin adhesives in otolaryngology. Some authors pointed out that fibrin tissue adhesive is not only a hemostatic, but also a bacteriostatic agent ${ }^{(8)}$. In case of endonasal operations, fibrin sealing was proposed in endonasal-transsphenoidal pituitary surgery more that a decade ago ${ }^{(9)}$. The authors did not use the fibrin glue to stop bleeding but to fix the mucoperichondrium. They admitted that a firm fixing of the margins of a mucoperichondrial laceration to the septal cartilage creates conditions for optimal healing and reduces nasal-packing time and nasal-splinting time. We successfully use the second-generation surgical fibrin sealant Quixil ${ }^{\mathrm{TM}}$ to treat epistaxis ${ }^{(10,11)}$.

The current prospective, randomized study was made to investigate glue properties of the fibrin sealant in cases of septoplasty and to confirm its heamostatic properties in cases of conchotomy and septoplasty. We hypothesised that the fibrin glue might help to avoid nasal packing in cases of conchotomy/septoplasty and might help to avoid suturing in cases of septoplasty.

\section{MATERIALS AND METHODS \\ Patients}

One hundred and forty-six patients with deviated nasal septum and/or hypertrophy of the inferior conchae (inclusion criterium) $(n=128)$, and the nasal crest of the maxillary bone undergoing septoplasty, conchotomy, and septoplasty + conchotomy were entered into a prospective study. The study was approved by the Hospital Medical Ethics Committee. Our series includes patients with deviated nasal septum, many of whom also had hypertrophy of the inferior conchae as a result of chronic, vasomotor or allergic rhinitis. Patient data, such as age, sex, and affected part are shown in Table 1. Sixty-six of patients were female, and 80 were male. One hundred and twenty seven patients had no prior nasal surgery, 19 patients were operated before. Ten of them had nasal septum surgery and 
Table 1. Distribution of patients: age, sex, and affected part of nasal septum

\begin{tabular}{lccccccc}
\hline Total & \multicolumn{2}{c}{ Sex } & \multicolumn{3}{c}{ Age } & \multicolumn{2}{c}{ affected part } \\
cases & M & F & $18-25$ & $26-45$ & $46-62$ & anterior & posterior \\
\hline 146 & 80 & 66 & 42 & 69 & 35 & 128 & 18 \\
\hline
\end{tabular}

nine had conchotomy. Eleven patients suffered with arterial hypertension. Difficulties in nasal breathing were found in all 146 patients. Forty-one patients complained of snoring, 20 patients complained of sleep apnea. These patients were hospitalized for sleep monitoring. Thirty-three patients suffered with chronic sinusitis. Twenty-two patients complained of visibly deviated, asymmetric nose. These symptoms were evaluated before and after surgery by using anterior rhinoscopy and endonasal endoscopy, and also subjectively evaluated by the patients. Patients with hypertrophy of the inferior conchae were assigned to conchotomy, patients with deviated nasal septum were assigned for septoplasty, and patients with both pathologies were assigned to septoplasty + conchotomy surgery.

Patients were randomly assigned (double blind sealed envelope method) to one of two treatment groups: Group I ( $n=74)$, septoplasty and/or conchotomy + transseptal suturing (suturesupporting sealing) + fibrin glue (haemostatic); Group II $(n=72)$, septoplasty and/or conchotomy + fibrin glue (septal sealant) + fibrin glue (hemostatic).

\section{The fibrin glue and an application device}

Quixil $^{\mathrm{TM}}$ (Omrix, Belgium) is a surgical sealant based on a concentrate of human clottable proteins (virus inactivated concentrated cryo) and a highly purified native human thrombin. In fact, this is a fibrin glue without fibrinogen. Unlike conventional sealants based on bovine thrombin and purified fibrinogen, collagen or synthetic compounds (first generation glues), Quixil $^{\mathrm{TM}}$ attached firmly to tissue achieving instant haemostasis. Quixil ${ }^{\mathrm{TM}}$ is a biological product of human origin (second generation glue), which is metabolized naturally within several days without causing inflammation and crusts. The properties of the glue were described in detail in our previous publications ${ }^{(1-3,10,11)}$.

The amount of the sealant required depends upon the area of tissue to be treated. In case of endonasal operations, the amount is small. The fibrin glue is sprayed with the help of compressed air onto the tissue in short bursts $(0.1-0.2 \mathrm{ml})$ to produce a thin, even layer. If the haemostatic effect is not complete, a second layer should be applied. Quixil is metabolized by the physiological fibrinolytic system and absorbed, in the same way as an endogenous clot ${ }^{(12)}$.

Quixil is not known to interact with any other drug. There are concerns about transmission of slow viruses through human products. To minimize the risk of transmission of infective agents, stringent controls are applied to the selection of blood donors and donations. In addition, two consecutive virus removal and/or inactivation procedures are included in the glue production process. For clottable proteins this is Solvent/Detergent (S/D) treatment and pasteurisation; and for thrombin this is S/D treatment and virus filtration.

The fibrin sealant was applied through a pre-assembled application device featuring the MixJect vital transfer mechanism (Omrix, Belgium). This is a dual-syringe delivery system. Unlike previously used dual-syringe systems ${ }^{(13)}$, the MixJect is connected to an air regulator capable of delivering 2-4 bars of pressure, that is low and approximately corresponds with the air pressure of routine nasal aerosol sprays. The air pressure helps to distribute the glue in an aerosol form over the operative site. The syringe itself is designed in such a way that all clottable proteins and the thrombin concentrates are mixed passively in a syringe hub connector, just prior to contact with the repair site. It ensures quick aspiration of the reagents into the application device.

\section{Surgical Technique}

In both groups, the surgery was performed under local anaesthesia by using nasal packing soaked in a cocaine solution for 10 to 15 minutes. Then the nasal mucosa was injected with $0.1 \%$ Mercaine with Adrenaline $(1: 100,000)$. Turbinectomy with scissors and submucosal resection was used for conchotomy.

The mucopechondrium was elevated from one side. After the ridge is removed, the chondroplasty was performed. Our technique is based on a plastic of a deviated portion of the quadrangular cartilage. We use resection only in cases when the nasal septum is severely deformed. In both groups, a standard technique was used for conchotomy.

Group I: Transseptal suturing was used for additional security against postoperative intraseptal hematoma. Any cavity left in the intraseptal space could accumulate blood. For this group, to fix the mucoperichondrium and to avoid hematoma in intraseptal cavities, anterior portion of the septum was approximated with three to five through and through sutures (septal mattress sutures) in all cases. The surgical incision was closed with absorbable sutures. We used 4-0 Vicryl for the suturing. In cases with deformity of the posterior part, suturing of the posterior portion of the septum was hard to perform and a small incision in the mucoperichondrium was made from one side at the basis of the septum. The fibrin glue was sprayed on the operative site from both sides to fix the mucoperichondrium and to stop intraseptal bleeding (suture-supporting sealing).

Group II: After chondroplasty, the fibrin glue was sprayed between mucoperichondrium and cartilage to fix them and prevent bleeding and intraseptal hematoma (face-to-face sealing).

Subserquently in both types of operations and in both Groups, fibrin glue was sprayed in amount of $0.5 \mathrm{cc}$ into each nostril to achieve complete haemostasis in the whole operation site. Bearing in mind the anatomy of the nasal passages, we inserted an applicator tube in the posterior part of the nose towards the turbinates. The nozzle did not touch the tissue. Then we 
Table 2. Types of operations performed during the study.

\begin{tabular}{lcc}
\hline & Group I & Group II \\
\hline Septoplasty & 4 & 4 \\
Conchotomy (turbinectomy) & 20 & 23 \\
Septoplasty + conchotomy (turbinectomy) & 50 & 45 \\
\hline TOTAL & 74 & 72 \\
\hline
\end{tabular}

start depositing the aerosol glue in the region of turbinates moving the applicator tube outward. Only by moving the nozzle out can we achieve good even intranasal distribution of the glue.

Because of the absence of postoperative haemorrhage (due to the biophysical properties of the fibrin sealant), a nasal packing was not necessary. Therefore, there was no need for an administration of antibiotics. The patients were able to leave the hospital immediately after the surgical procedure. They needed no postoperative care.

For both groups, follow-up visits were scheduled the next day, the third day, two weeks, and one month after surgery. The VAS pain scale was used for pain assessment.

\section{Statistics}

The data were statistically evaluated by one-dimensional analysis of variance, SPSS, Standard version 10.0.5 (SPSS, Chicago, IL, 1999), and $\chi^{2}$ criterion using $95 \%$ confident interval. The level of significance for all analyses was set at $\mathrm{p}<0.05$.

\section{RESULTS}

Our current series included conchotomy and septoplasty. The types of operations are shown in Table 2. The results of these surgical procedures were assessed objectively in the clinic by anterior rhinoscopy and endoscopy of the nasal cavity and assessed subjectively by the patients at the above mentioned follow-up visits.

All the patients in Groups I and II showed complete resolution of their major symptoms. We found good tissue approximation, no hematomas, swelling, synechiae, atrophic changes or adhesions, and no septal displacement. No postoperative bleeding occurred except one episode of late bleeding in Group I (2.08\%). There were no other complications in this series. We found no statistical difference between Groups I and II in terms of postoperative bleeding or other complications. There were no allergic reactions to the glue in our study.

Regarding pain endured, patients in Group I, where transseptal suturing was used, experienced statistically more pain compared to the Group II $(\mathrm{p}<0.02)$.

\section{DISCUSSION}

The surgical treatment for chronic, vasomotor, and allergic rhinitis with hyperthrophy of inferior conchae is proposed when medical therapy is unsatisfactory. The surgical treatment for deviated nasal septum is the only treatment possible.
Already in 1987, Hayward and Mackay successfully used fibrin glue in nasal septal surgery ${ }^{(14)}$. These authors, however, used the glue mostly as a filling, by injecting it between the layers of mucoperichondrium to fill the position from which cartilage had been removed. They used Duploject applicator, which cannot be connected to a pressed air regulator and, therefore, a pressure-driven aerosol spray cannot be achieved. That is why they were unable to use the glue as a main haemostatic agent for the whole operative site. These authors used Telfa pack during the operation and mentioned "some spotting of fresh blood from the nose" during the first two post-operative days. We investigate properties of fibrin sealants since 1998. Our main innovations were the use an aerosol form of the fibrin glue to avoid bleeding and intraseptal hematoma in nasal septal operations even without additional suturing of the septum. The surgical technique was relatively easy to perform and was done after achievement of local anaesthesia. The convalescence was uneventful, and nasal ventilation was possible immediately after the operation.

We found no statistical difference between both face-to-face sealing and suture-supporting sealing groups in terms of occurrence of any postoperative bleeding and complications. The surgical procedure is relatively simple to perform and can be done with local anaesthesia, reducing the cost and duration of hospital stay. In addition to laser usage in endonasal operations, the usage of the fibrin glue is a convenient and simple method to avoid nasal packing. The fibrin sealant is safe and easy to use. It not only seals but being a human blood product also stimulates healing of the operated area and acts like a real "glue".

Suturing is an established technique in septoplasty. However, the main goal of the fibrin glue usage is not to avoid suturing, but to avoid nasal packing. This will be the main benefit for a patient in any kind of endonasal operations. Specifically for septoplasty, the benefit is doubled because we can avoid both nasal packing and suturing. Furthermore, sometimes it might be technically difficult to suture the posterior part of the septum and some risk of bleeding might remain. While the aerosoled glue covers all perychondrial cavity, this risk is minimized.

Our observations proved previous reports that the dual-syringe delivery system is especially useful for applying the fibrin sealant onto small body surfaces ${ }^{(15)}$. In case of endonasal operations, the aerosol spraying technique helps to stop the bleeding in all parts of the nasal cavity.

In both Groups, there were no transient or chronic infections. We feel this is due to the properties of the Quixil ${ }^{\mathrm{TM}}$ human fibrin sealant and the modified surgical technique. In our cases, there was no need to apply a second layer of the sealant and no crusts were detected. In fact, the fibrin glue produced no plaques; therefore there was no danger for their aspiration.

\section{CONCLUSION}

We found the results of this series to be encouraging. The 
human fibrin sealant is well suited to stop bleeding after septoplasty and conchotomy operations if used in aerosol form. It can be successfully used as a sealant in septoplasty. It does not only stop bleeding but being a human blood product also stimulates healing of the operated area. The transseptal suturing combined with the glue is not justified for the patients as no statistical difference was observed between the Groups I and II in terms of occurrence of postoperative complications.

\section{REFERENCES}

1. Vaiman M., Eviatar E, Segal S. The use of fibrin glue as hemostatic in endonasal operations: prospective randomized study. Rhinology. 2002; 40: 185-188.

2. Vaiman M, Eviatar E, Segal S. Effectiveness of second generation fibrin glue in endonasal operations. Otolaryngol Head Neck Surg. 2002; 4: 388-391.

3. Vaiman M, Eviatar E, Shlamkovich N, Segal S. The use of fibrin glue as hemostatic in endoscopic sinus surgery. Annals Otol Rhinol Laryngol. 2005; 114: 237-241.

4. Boenisch M, Nolst Trenité GJ. Fibrin glue for operative correction of septal deviations. HNO 2004; 52: 963-937.

5. Avizar R. Using fibrin glue in endonasal surgery. Isr Med Assoc J. 2005; 7: 823.

6. Yano S, Tsuiki H, Kudo M, Morioka M, Takeshima H, Yumoto E, Kuratsu J. Sellar repair with resorbable polyglactin acid sheet and fibrin glue in endoscopic endonasal transsphenoidal surgery. Surg Neurol. 2007; 67: 59-64.

7. Loré JM. An Atlas of Head and Neck Surgery. Philadelphia: W.B. Sauders Co., pp. 1988. 212-235.

8. Gleich LL, Rebeiz EE, Pankratov MM, Shapshay SM. Autologous fibrin tissue in endoscopic sinus surgery. Otolaryngol Head Neck Surg. 1995; 112: 238-241.
9. D'Arrigo C, Landolt AM. Fibrin sealing of mucoperichondrial flaps in endonasal-transsphenoidal pituitary surgery: technical note. Neurosurgery. 1994; 35: 529-531.

10. Vaiman M, Segal S, Eviatar E. Fibrin glue treatment for epistaxis. Rhinology. 2001; 40: 133-135.

11. Vaiman M, Martinovich U, Segal S, Eviatar E. Fibrin glue in initial treatment of epistaxis in hereditary hemorrhagic telangiectasia (Rendu-Osler-Weber Disease). Blood Coagulation \& Fibrinolysis. 2004; 15: 359-363.

12. Quixil: Summary of Product Characteristics. OFI SPC Draft 5, 3-6, 2000.

13. Redl H, Schlag G. Fibrin Sealant and its Modes of Application. In: Redl H, Schlag G., (Eds.) Fibrin Sealant in Operative Medicine. Berlin - New York: Springer-Verlag, 1986; vol. 1, pp. 13-26

14. Hayward PJ, Mackay IS. Fibrin glue in nasal septal surgery. J Laryngol Otol. 1987 101: 133-138.

15. Radisevich M, Goubran HA, Burnouf T. Fibrin sealant: scientific rationale, production methods, properties, and current clinical use. Vox Sang. 1997; 72: 133-143.

\section{Michael Vaiman 33 Shapira Str Bat Yam 59561 Israel}

Tel: +9723-553-6139

Fax: +9723-553-6137

E-mail: vaimed@yahoo.com 